\title{
Isolation and Molecular Detection of Infectious Bronchitis Virus Isolates from Chicken
}

\author{
K.T. Shyma ${ }^{1}$, Surya Sankar ${ }^{1 *}$, T.V. Aravindakshan ${ }^{2}$, K. Krithiga ${ }^{3}$, \\ Anu Bosewell ${ }^{1}$, N. Sarika ${ }^{1}$ and M. Mini ${ }^{1}$ \\ ${ }^{1}$ Department of Veterinary Microbiology, ${ }^{2}$ School of Applied Animal Production and \\ Biotechnology, ${ }^{3}$ Department of Veterinary Pathology, College of Veterinary and Animal \\ Sciences, Mannuthy, 680651, Kerala, India \\ *Corresponding author
}

\section{Keywords}

Infectious bronchitis virus, Isolation, Partial hypervariable region of spike gene

\section{Article Info}

Accepted:

20 September 2018

Available Online:

10 October 2018

\section{A B S T R A C T}

All over the world, Infectious bronchitis (IB) is one of the most fearful diseases of the poultry industry causing significant economic loses. The present study was aimed at the isolation, identification and molecular characterisation of IBV isolates. For the present study, samples were collected from chicken of different age groups that have shown signs of respiratory tract infection. The specific UP and DOWN primers targeting the highly conserved region of 5'UTR were used for the detection of IBV and the positive samples were selected for further characterization. The hypervariable region of spike gene was amplified by RT-PCR and sequenced to study the genetic diversity between the isolated viruses. All samples were also inoculated onto nine to eleven day old specific pathogen free embryonated chicken eggs via, allantoic cavity. After harvesting, allantoic fluid was collected and RT-PCR was conducted for confirmation. Phylogenetic tree was constructed with the help of MEGA 7 software using maximum likelihood method by including bootstrap values for analysing the evolutionary pattern of IBV isolates. Out of the 20 samples collected, seven were positive for IBV using specific UP and DOWN primers. Virus inoculated embryos after seventh blind passage showed curling and dwarfing, which is the characteristic lesion of IBV. The hyper variable region of spike gene of all the positive isolates were amplified by RT-PCR and sequenced to study the genetic diversity of the isolated viruses. The sequences of the isolates were found to have identity with each other, and with the sequences of commercial vaccine strains available in NCBI GenBank database, slight variations were detected. Phylogenetic tree revealed that IBV isolates obtained in our study were similar to the isolates from various other countries including Indian isolates. It is necessary to study the genetic variation in the IBV isolated from particular geographical areas, which in turn could help us in developing an area specific vaccination programme to combat the disease. 


\section{Introduction}

Avian infectious bronchitis virus which belongs to the family Corona viridae is an acute, highly contagious disease of chickens affecting birds of all age groups. Infectious bronchitis virus mainly affects the chicken, and various avian species like geese, duck, guinea fowl and pigeon are also susceptible (Cavanagh, 2005; Cavanagh, 2007). It mainly affects the respiratory tract, kidney and reproductive system of chicken and various other avian species.

The chicken infected with infectious bronchitis virus (IBV) shows clinical signs like sneezing, tracheal coarse crackles, coughing, and reduction in feed intake. Infectious bronchitis (IB) causes substantial economic losses throughout the poultry industry around the world (Feng et al., 2017). In layers, it decreases the egg production and egg quality as a result of thin, fragile, misshapen shells and thin watery eggs (Cavanagh and Naqi, 2003; Worthington et al., 2008).

Infectious bronchitis viruses are enveloped virus possessing round to pleomorphic shape. The viral genome comprises a single-stranded positive sense RNA having a size approximately 27.5 to $28 \mathrm{~Kb}$ and mainly encodes four structural proteins such as spike (S), envelope (E), membrane (M), and nucleocapsid $(\mathrm{N})$ proteins (Jackwood and de Wit., 2013). The spike glycoprotein is subdivided in to $\mathrm{S} 1$ and $\mathrm{S} 2$ after posttranslational cleavage. The $\mathrm{S}$ protein shows marked diversity in their nucleotide sequence. The most distinguished characteristics of this virus among other corona viruses are the high frequency of generation of new variants. Many serotypes have been identified for IBV due to point mutations, genetic recombination events and also due to selective pressure in the hyper variable regions of the genome (Liu et al., 2007; Jackwood et al., 2012). Therefore, a region wise characterisation of virus isolates which exists in the field conditions is very important. More than 50 serotypes have been detected for IBV and new variants are emerging despite the use of live attenuated and killed IBV vaccines (Saadat et al., 2017).

In Kerala, vaccination against IB is usually not practiced, but very few reports are there regarding outbreaks of the disease in the state. Under these circumstances, the present study was undertaken to isolate IBV from chicken in embryonated chicken eggs (ECE) and its standardisation by Reverse-TranscriptasePolymerase Chain reaction (RT-PCR) assay for detection followed by sequencing and comparison of sequences with that of commercial vaccine strain.

This could help in formulating an area specific vaccination strategy using local strains, thereby combating the disease.

Therefore the present study was envisaged to isolate and characterise IBV employing an RT-PCR targeting the partial hypervariable region of spike gene followed by sequencing.

\section{Materials and Methods}

\section{Tissue sample collection}

In the present study, 20 tissue samples including kidney, liver, spleen, oviduct, trachea, air sacs and lungs were collected from chicken suspected of having respiratory tract infections in sterile RNAse free vials containing RNA later solution from University Poultry Farm, birds brought to the Department of Veterinary Microbiology and Veterinary Pathology, College of Veterinary and Animal Sciences, Mannuthy, Thrissur for disease investigation and also from organized farms in Thrissur district. All the samples were kept at $-20^{\circ} \mathrm{C}$ until RNA extraction. 


\section{Isolation of infectious bronchitis virus}

The supernatant from twenty samples were inoculated via allantoic route on to embryonated chicken eggs (9-11 day old). The eggs were candled daily and the embryos that were found live were kept up to seven days before harvesting. Allantoic fluid was harvested and RT-PCR was conducted employing extracted RNA from the allantoic fluid.

\section{Trizol method of RNA extraction}

Viral RNA was extracted from $250 \mu 1$ supernatant of the processed tissue samples as well as from the allantoic fluid harvested from the inoculated ECE according to the standard protocol of Trizol method of RNA extraction (Ahmad et al., 2007). The subsequent reverse transcription was done for synthesizing cDNA or the RNA was stored at $-70{ }^{\circ} \mathrm{C}$ for later use.

\section{Complementary DNA (cDNA) synthesis}

RNA extracted from the processed tissue samples and harvested allantoic fluid was subjected to RT-PCR to synthesise cDNA in a $20 \mu$ reaction mixture, using Verso cDNA synthesis kit (Thermo Scientific, USA) according to the manufacturer's instructions. Briefly, the reactions were set up in $0.2 \mathrm{ml}$ PCR tubes containing $5 \mu \mathrm{l}$ of template RNA, $1 \mu \mathrm{l}$ of Random hexamer primer $(400 \mathrm{ng} / \mu \mathrm{L}), 6$ $\mu \mathrm{l}$ of Nuclease free Water, $4 \mu \mathrm{l}$ of $5 \mathrm{X}$ reaction buffer, $1 \mu 1$ of RT enhancer, $2 \mu 1$ of $10 \mathrm{mM}$ dNTP mix (5 mM each) and $1 \mu$ of Verso enzyme mix. Master mix was prepared excluding template RNA sample and nuclease free water, which were added individually to each reaction tube. The reaction mix was incubated for an initial incubation at $25^{\circ} \mathrm{C}$ for five minutes followed by $42^{\circ} \mathrm{C}$ for one hour followed by $70^{\circ} \mathrm{C}$ for five minutes. The resultant cDNA was immediately used in PCR or stored at $-20{ }^{\circ} \mathrm{C}$ for later use.

\section{Detection of IBV}

Polymerase chain reaction was performed to amplify a fragment of 5'UTR gene using specific IBV UP and DOWN primers which were custom synthesised commercially (Sigma Aldrich). The sequences and other parameters of the primers are presented in Table 1. Polymerase chain reaction for the amplification of $143 \mathrm{bp}$ was performed in a $12.5 \mu \mathrm{L}$ reaction volume containing $2 \mu \mathrm{L}$ of cDNA, $6.25 \mu \mathrm{L}$ of Taq Mix 2X, $10 \mathrm{pM}$ each of forward and reverse primers. The cycling parameters were $95{ }^{\circ} \mathrm{C}$ for $10 \mathrm{~min}, 35$ cycles of $95{ }^{\circ} \mathrm{C}$ for $45 \mathrm{~s}, 53{ }^{\circ} \mathrm{C}$ for $1 \mathrm{~min}, 72^{\circ} \mathrm{C}$ for 1 min and a final extension at $72{ }^{\circ} \mathrm{C}$ for $10 \mathrm{~min}$ and products were resolved using $2 \%$ agarose gel electrophoresis.

\section{Sequencing of S1 gene}

A region corresponding to $257 \mathrm{bp}$ of partial hypervariable region of spike gene was amplified by PCR using IBV $3 \mathrm{~F}$ and $3 \mathrm{R}$ primers (Table 2). The PCR reaction was carried out in $12.5 \mu \mathrm{l}$ mixture containing 6.25 $\mu \mathrm{L}$ of Taq Mix $2 \mathrm{X}, 10 \mathrm{pM}$ of each forward and reverse primer and $2 \mu \mathrm{l}$ cDNA as template. The thermal cycling profile for the reaction includes initial denaturation for $5 \mathrm{~min}$ at $95^{\circ} \mathrm{C}$, followed by 35 cycles of denaturation at $95^{\circ} \mathrm{C}$ for $30 \mathrm{sec}$, annealing at $44.4^{\circ} \mathrm{C}$ for 45 sec, extension at $72^{\circ} \mathrm{C}$ for $1 \mathrm{~min}$ and final extension at $72^{\circ} \mathrm{C}$ for $7 \mathrm{~min}$. The amplified products were then resolved in $2 \%$ agarose gel electrophoresis and visualised in UV transilluminator (Bio Rad, USA) after staining with ethidium bromide and were sequenced using forward and reverse primers.

Sequencing was performed by automated sequencer using Sanger's dideoxy chain termination method at Xcelris Labs Limited, Ahmedabad. The obtained sequences were aligned with other sequences of IBV available in GenBank using BLASTn. 


\section{Phylogenetic analysis}

The nucleotide sequence data of our isolate from Thrissur, Kerala was submitted to the GenBank sequence database and have been assigned the accession number MH667320. Phylogenetic tree was constructed using the Maximum Likelihood method using the MEGA version 7 software.

For the phylogenetic studies our isolate was compared with other sequences of partial spike glycoprotein of $\mathrm{S} 1$ subunit of IBV available in the GeneBank.

\section{Results and Discussion}

\section{Viral RNA extraction and RT-PCR}

RNA was extracted from the processed tissue and harvested allantoic fluid from 20 samples using Trizol method. Extracted RNA was subjected to RT-PCR to detect the virus, employing IBV UP and DOWN primers. The mean ratio of optical densities of the extracted RNA samples at 260/280 nm and 260/230 nm were $2.02 \pm 0.17$ and $2.13 \pm 0.15$, respectively. The cDNA synthesis was performed from the extracted RNA using verso first strand cDNA synthesis kit (Thermo Scientific, USA).

\section{Detection of infectious bronchitis virus}

In the present study, cDNA from 20 samples were subjected to RT-PCR to detect the virus employing IBV UP and DOWN primers. Among them, seven were positive which revealed an amplicon size of 143 bp (Fig. 1).

\section{Propagation of virus in embryonated chicken eggs}

The supernatant from all the twenty samples was inoculated via allantoic route on to embryonated chicken eggs (9-11 day old). The embryo inoculated with IBV exhibited lesions such as curling and dwarfing and urate deposits in allantoic fluid on seventh passage (Fig. 2).

\section{Sequencing and sequence analysis}

The partial sequences of S1 gene of all the seven isolates were successfully amplified using in-house designed IBV3 F and $3 \mathrm{R}$ primers and PCR amplicons of $257 \mathrm{bp}$ size was obtained (Fig. 3) and were sequenced by Sanger's dideoxy chain termination method using the forward and reverse primers. The sequenced reads were merged using EMBOSS merger to obtain the sequences of IBV and further analysed. The sequences were queried in the nucleotide database and blasted to confirm that the BLASTn hits were of IBV sequence. The sequences of the isolates obtained were compared with each other and with that of the vaccine strains (M41, H120, and Massachusetts). The sequences obtained from the current study showed $98 \%$ similarity with the commercial vaccine strains of IBV. Between the seven isolates obtained in the study, no detectable variations could be observed, and this might be attributed to the fact that samples collected for the study were from a small geographical area within Thrissur district. Hence, an elaborate study covering representative geographical areas within the state could provide a comprehensive data regarding the variants of IBV circulating, which could provide adequate data for the implementation of vaccination strategy to control the disease.

\section{Phylogenetic analysis}

Phylogenetic analysis was performed with our isolate and other isolates available in GenBank. The IBV isolate obtained from the present study showed close relatedness to other isolates from India (UP, MP, Gujarat and Kashmir) along with isolates from other countries (Fig. 4). 
Fig.1 Agarose gel electrophoresis of PCR amplified products of 5'UTR (143 bp)

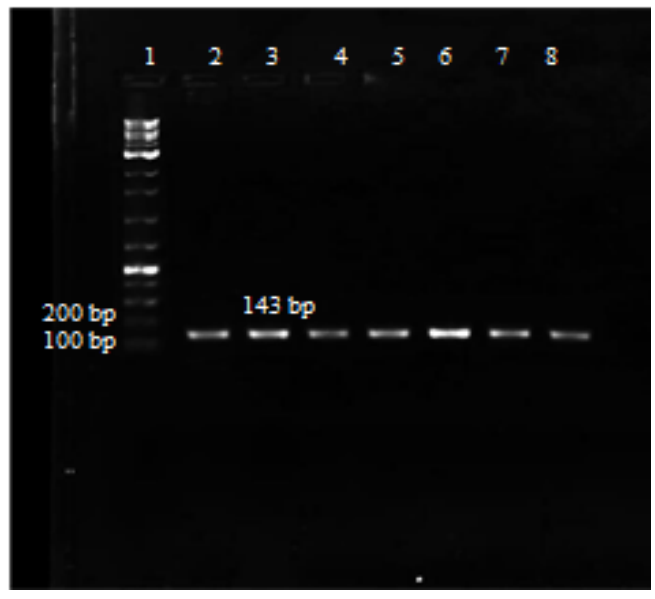

Fig.2 Control: $15^{\text {th }}$ day old healthy embryo, sample: embryo infected with infectious bronchitis virus showing characteristic lesions such as curling and dwarfing

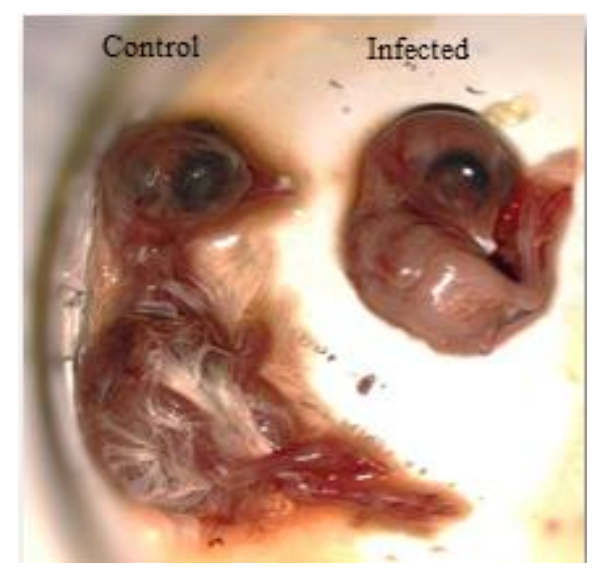

Fig.3 Agarose gel electrophoresis of PCR amplified products of partial spike gene (257 bp)

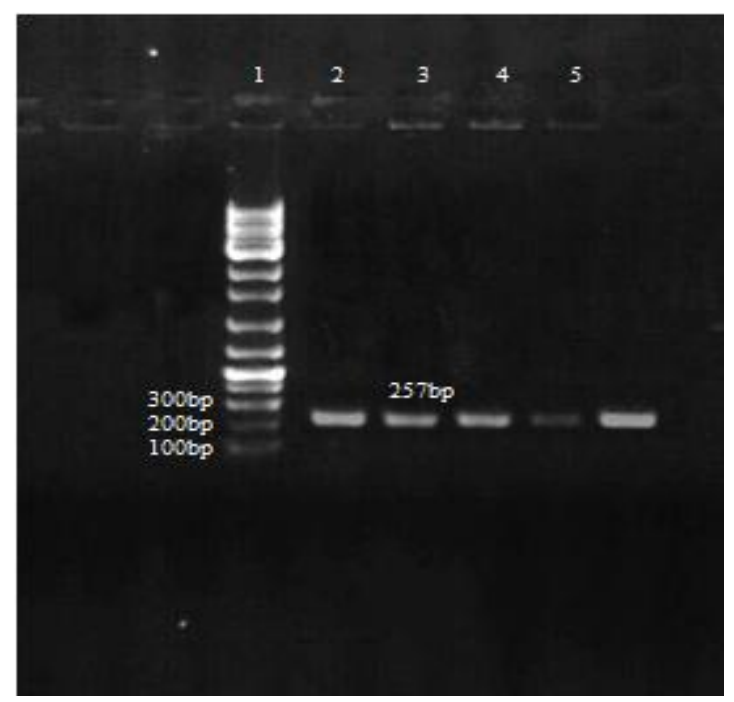


Fig.4 Phylogenetic analysis based on nucleotide acid sequence of partial spike gene

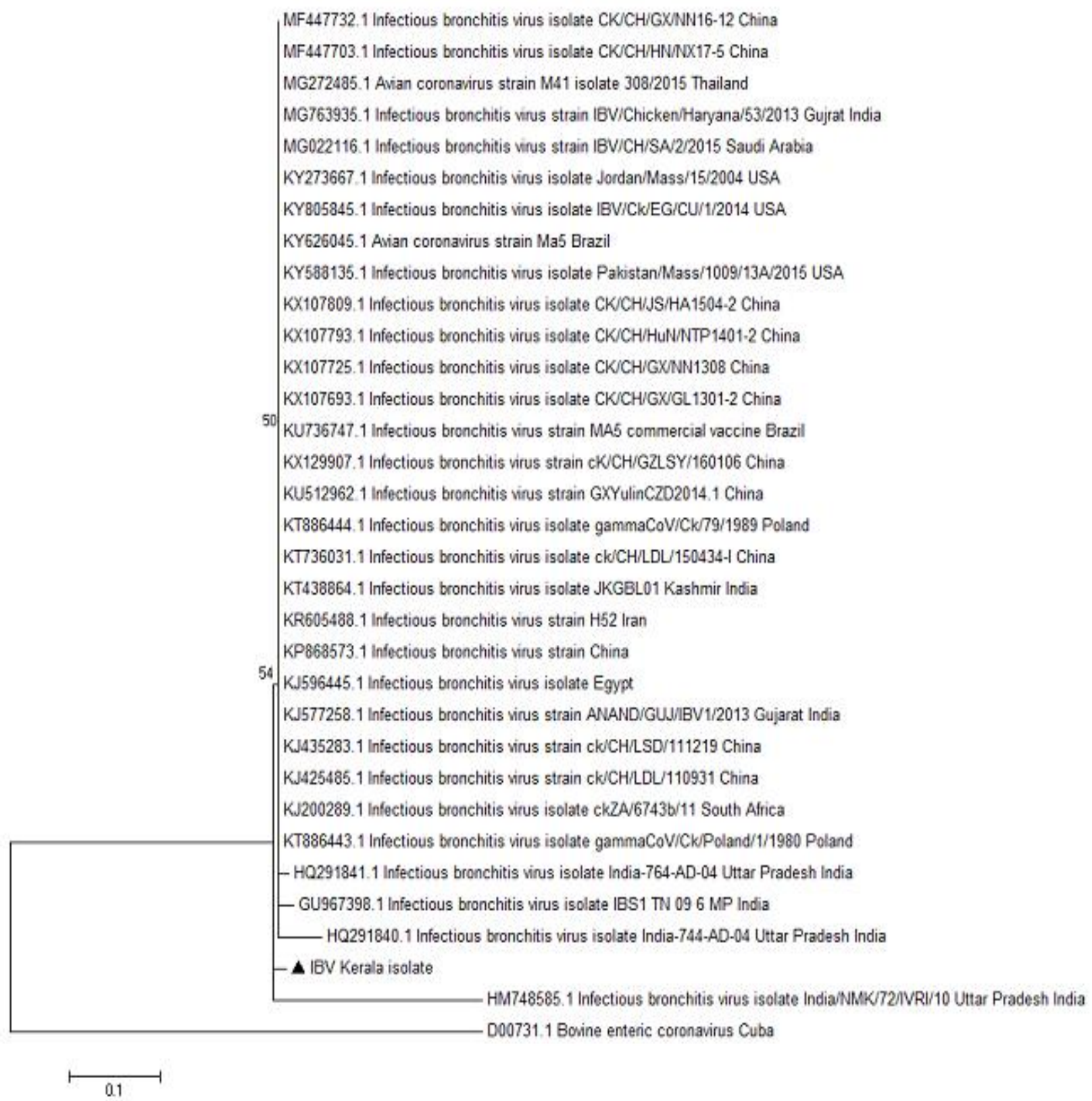

Table.1 Parameters and sequences of primers specific for the infectious bronchitis virus

\begin{tabular}{|c|c|c|c|c|}
\hline $\begin{array}{c}\text { SI } \\
\text { No }\end{array}$ & $\begin{array}{c}\text { Primer } \\
\text { name }\end{array}$ & Primer sequence (5’-3') & $\begin{array}{l}\text { Product } \\
\text { size (bp) }\end{array}$ & Reference \\
\hline 1 & IBVUP & GCTTTTGAGCCTAGCGTT & \multirow[t]{2}{*}{143 bp } & \multirow{2}{*}{$\begin{array}{c}\text { Callison } e t \\
\text { al., } 2007\end{array}$} \\
\hline 2 & IBVDOWN & GCCATGTTGTCACTGTCTATT & & \\
\hline 3 & IBH3F & AATCCTAGTGGTGT YCAG & \multirow[t]{2}{*}{$257 \mathrm{bp}$} & \multirow{2}{*}{$\begin{array}{c}\text { Jain et al., } \\
2017\end{array}$} \\
\hline 4 & IBH3R & GTTGCTCTACCACTAAAG & & \\
\hline
\end{tabular}


Bovine corona virus showed divergence to IBV isolates thus forming the out group.

Infectious bronchitis is a significant disease affecting chicken and many other avian species, which is acute and contagious in nature. The disease affects the respiratory tract, kidney and reproductive system of birds and the important manifestations are coughing, sneezing, gasping, tracheal rales, decrease in weight gain, feed conversion efficiency and reduction in quality and quantity of eggs (Callison et al., 2001).

In Kerala, so far no vaccination programmes are there against the disease. So, there is an urgent need for an area wise genotypic characterisation of the virus, which in turn could help in advocating a region specific vaccination strategy to combat the disease. Hence, the current study was commenced as a pilot one to isolate, identify and genotypically characterise the IBV from cases of respiratory infections in chicken.

RNA was extracted from the processed tissue samples and harvested allantoic fluid was subjected to RT-PCR assay for the identification of IBV. Reverse-transcriptase PCR assay was found to be a highly sensitive tool for the identification and molecular characterisation of the virus (OIE, 2008). The specific primers used in the present study targeted a highly conserved region of 5 'UTR. Out of the 20 samples subjected to PCR, an expected amplicon of $143 \mathrm{bp}$ was yielded only from seven samples. As per Callison et al., (2006) primers targeting the 5 'UTR was found to be highly specific for IBV detection. Bich et al., (2017) and Patel et al., (2015) have also documented the specificity of 5 , UTR based primers for the identification of the virus. Real-time PCR based detection of the virus was mainly concentrated on conserved 5 'UTR gene. Conventional RTPCR was found to be less sensitive than real- time PCR for detecting IBV (Callison et al., 2007, Meir et al., 2010 and Acevedo et al., 2013).

For molecular characterisation of IBV, primers were designed targeting the hypervariable region of spike gene (S1). The seven samples that turned positive with detection primers were subjected to RT-PCR employing primers targeting the variable region. The IBV evolution are mainly scrutinized by spike gene analysis because of the marked variation in the nucleotide sequences especially in the hyper variable region and is an effective tool to type strains by RT-PCR and sequencing (Cavanagh et al., 1991). In the present study, 257 bp amplicons of the partial S1 gene of the IBV isolates were subjected to Sanger's sequencing. The sequences of the isolates obtained were compared with each other and with that of the vaccine strain. The sequences obtained from the current study showed $98 \%$ similarity with the commercial vaccine strains of IBV (M41, H120, and Massachusetts) and variations were found to be two per cent.

These findings could be compared with the findings of Kamble et al., (2016) where Indian isolates shared a $71.8 \%-99 \%$ similarity with the sequenced H120 strain. Between the seven isolates obtained in the study, no detectable variations could be observed, and this might be attributed to the fact that samples collected for the study were from a small geographical area within Thrissur district. Hence, an elaborate study covering different geographical areas within the state could provide a comprehensive data regarding IBV variants circulating in the state, which could help in the identification of vaccine strains and development of vaccination strategies to control the disease.

Avian infectious bronchitis (IB) is an acute and severe disease affecting respiratory tract, 
kidney and reproductive tract of chicken and a variety of other avian species, causing unreliable economic loses to the poultry industry all over the world. Out of 20 samples taken for the present study, seven isolates could be obtained. The positive amplicons were sequenced and the results were compared with each other and with that of the commercial vaccine strains used in the country.

There were no detectable variation in the sequences between the isolates but with vaccine strains, the isolates showed about two per cent variations in their nucleotide sequences. Since the study is a pilot one restricted to a small geographical area within Kerala, an elaborate study is required covering the entire state to identify the prevalent strains circulating so as to implement policies towards the vaccination of IB in the state.

\section{Acknowledgment}

We are very thankful to the Kerala Veterinary and Animal Sciences University for providing the facilities needed for the conduct of research.

\section{References}

Abdel-Moneim, A.S., Madbouly, H.M. and ElKady, M.F. 2005. In vitro characterization and pathogenesis of Egypt/BeniSuef/01; a novel genotype of infectious bronchitis virus. Journal of Veterinary Medicine 15(20): 127-133.

Acevedo, A.M., Perera, C.L., Vega, A., Ríos, L., Coronado, L., Relova, D., Frías, M. T., Ganges, L., Nunez, J. I. and Pérez, L.J. 2013. A duplex SYBR Green I-based real-time RT-PCR assay for the simultaneous detection and differentiation of Massachusetts and non-Massachusetts serotypes of infectious bronchitis virus.
Molecular and Cellular Probes 7(5-6): 184-192.

Adebiyi, A.I and Fagbohun, A.F. 2017. Infectious bronchitis virus in captured free-living, free range and intensively reared birds in southwest Nigeria. Folia Veterinaria 61(1): 23-26.

Ahmad, Z., Naeem, K. and Hameed, A. 2007. Detection and seroprevalence of infectious bronchitis virus strains in commercial poultry in Pakistan. Poultry Science 86: 1329-1335.

Bich, T.N., Khanh, N.P., Dung, P.H. and Loan, N.T.C. 2017. Molecular characterization of infectious bronchitis virus (IBV) isolated from commercial chicken arms. Can Tho University Journal of Science 6: 56-62.

Callison, S.A., Hilt, D.A., Boynton, T.O., Sample, B.F., Robison, R., Swayne, D.E. and Jackwood, M.W. 2006. Development and evaluation of a real-time Taqman RTPCR assay for the detection of infectious bronchitis virus from infected chickens. Journal of Virological Methods 138: 6065.

Callison, S.A., Jackwood, M.W. and Hilt, D.A. 2001. Molecular characterization of infectious bronchitis virus isolates foreign to the United States and comparison with United States isolates. Avian Diseases 45: 492-499.

Callison, S.A., Riblet, S.M., Oldoni, I., Sun, S., Zavala, G., Williams, S., Resurreccion, R.S., Spackman, E. and Garcia, M. 2007. Development and validation of a realtime Taqman PCR assay for the detection and quantitation of infectious laryngotracheitis virus in poultry. Journal of Virological Methods 139(1): 31-38.

Cavanagh, D. 1991. Sequencing approach to IBV antigenicity and epizootiology. In: Proceedings of the Second International Symposium on Infectious Bronchitis. Rauischholzhausen, Germany, June 1991, 147-160.

Cavanagh, D. 2005. Coronaviridae: a review of coronaviruses and toroviruses. In A. Schmidt. 
Cavanagh, D. 2007. Coronavirus avian infectious bronchitis virus. Veterinary Research 38: 281-297.

Cavanagh, D. and Naqi, S.A. 2003. In: Diseases of Poultry. Calnek, B. W., Barnes, H. J., Beard, C.W., McDougald, L. R. and Saif, Y.M. (Eds.), 11th edn. Ames, IA, Iowa State University Press, pp: 101.

Feng, K., Wang, F., Xue, Y., Zhou, Q., Chen, F., Bi, Y. and Xie. Q. 2017. Epidemiology and characterization of avian infectious bronchitis virus strains circulating in southern China during the period from 2013-2015. Scientific Reports 7: 65-76.

Jackwood, M.W. and DeWit, J. 2013. Infectious Bronchitis. Diseases of Poultry 139-159.

Jackwood, M.W., Hall, D. and Handel, A. 2012. Molecular evolution and emergence of avian gammacorona viruses. Infection Genetics and Evolution, 12: 1305-1311.

Kamble, N.M., Pillai, A.S., Gaikwad, S.S., Shukla, S.K., Khulape, S.A., Dey, S. and Mohan, C.M. 2016. Evolutionary and bioinformatic analysis of the spike glycoprotein gene of H120 vaccine strain protectotype of infectious bronchitis virus from India. Biotechnology and Applied Biochemistry 63(1): 106-112.

Liu, S., Han, Z., Chen, J., Liu, X., Shao, Y., Kong, X., Tong, G. and Rong, J. 2007. S1 gene sequence heterogeneity of a pathogenic infectious bronchitis virus strain and its embryo-passaged, attenuated derivatives. Avian Pathology 36(3): 231-234.
Meir, R., Maharat, O., Farnushi, Y. and Simanov, L. 2010. Development of a realtime TaqMan ${ }^{\circledR}$ RT-PCR assay for the detection of infectious bronchitis virus in chickens, and comparison of RT-PCR and virus isolation. Journal of Virological Methods 163: 190-194.

OIE. 2008. Manual of diagnostic tests and vaccines for terrestrial animals (mammals, birds and bees). OIE, Paris, France.

Patel, B., Bhimani, M., Bhanderi, B. and Jhala, M. 2015. Isolation and molecular characterization of nephropathic infectious bronchitis virus isolates of Gujarat state, India. Virus Diseases 26: 42-47.

Saadat, Y., Fard, M.H.B., Charkhkar, S., Hosseini, H., Shaikhi, N., Akbarpour. B. 2017. Molecular characterization of infectious bronchitis viruses isolated from broiler flocks in Bushehr province, Iran: 2014 - 2015. Veterinary Research Forum 8(3): $195-201$.

Surendar, A.P., Palanivel, K.M., Saravanan, S. and Gopala Krishnamurthy, R. 2017. Detection and Characterization of Infectious Bronchitis Virus in Desi Birds by Molecular Assay. International Journal of Current Microbiology and Applied Science 6(9): 1098-1102.

Worthington, K.J., Currie, R.J. and Jones, R.C. 2008. A reverse transcriptase-polymerase chain reaction survey of infectious bronchitis virus genotypes in Western Europe from 2002 to 2006. Avian Pathology 37: 247-257.

\section{How to cite this article:}

Shyma, K.T., Surya Sankar, T.V. Aravindakshan, K. Krithiga, Anu Bosewell, N. Sarika and Mini, M. 2018. Isolation and Molecular Detection of Infectious Bronchitis Virus Isolates From Chicken. Int.J.Curr.Microbiol.App.Sci. 7(10): 2858-2866. doi: https://doi.org/10.20546/ijcmas.2018.710.333 